\title{
Reversal of Diminished Inhibitory Sensory Gating in Cocaine Addicts by a Nicotinic Cholinergic Mechanism
}

Lawrence E. Adler, M.D., Ann Olincy, M.D., Ellen Cawthra, R.N., M.P.A., Michelle Hoffer, B.S., Herbert T. Nagamoto, M.D., Leslie Amass, Ph.D., and Robert Freedman, M.D.

Cocaine addiction, as with other stimulant abuse, produces psychotic symptoms. Although often moderate to mild in severity, these symptoms are, nevertheless, associated with poorer over-all outcome. Recent studies suggest diminished nicotinic cholinergic neurotransmission as a mechanism of a physiological deficit found in schizophrenia, failure of auditory sensory inhibition. Diminished inhibitory sensory gating also occurs in cocaine addicts, probably because of their increased catecholaminergic neurotransmission, which blocks the inhibition. In the present study, 11 cocaine addicts in the first week of detoxification were recorded electrophysiologically, after which the effects of $6 \mathrm{mg}$ of nicotine gum, were assessed in a double-blind placebocontrolled crossover design. The test was repeated 10 days later. Treatment with nicotine, but not placebo, briefly reversed the inhibitory abnormality on both test days. Although nicotine itself may not be a desirable therapeutic agent, because desensitization of nicotinic receptors limits the time course of its effect, the study identifies a previously unexploited therapeutic target for new drug development for the neuropsychiatric sequelae of cocaine addiction.

[Neuropsychopharmacology 24:671-679, 2001] (C) 2001 American College of Neuropsychopharmacology. Published by Elsevier Science Inc.
KEY WORDS: Cocaine abuse; Psychosis; Auditory evoked potential; Nicotine; Nicotinic receptors

Stimulant-induced psychosis is a classic psychotomimetic drug reaction (Angrist et al. 1974). Although this effect is most severe for methamphetamine and other amphetamine derivatives, it has also been reported in cocaine addicts (Brady et al. 1991). There is a significant rate of incidence of psychotic symptoms in cocaine powder abusers and an even higher rate among crack

From the Department of Psychiatry, University of Colorado Health Sciences Center, and Denver Veterans Affairs Medical Center Research Service, Denver, Colorado.

Address correspondence to: Lawrence E. Adler, M.D., Department of Psychiatry C-268-16, University of Colorado Health Sciences Center, 4200 East Ninth Avenue, Denver, CO 80262. Tel.: 303315-5358; Fax: 303-315-5347; E-mail: Lawrence.Adler@UCHSC.edu

Received 24 May 2000; revised 18 October 2000; accepted 31 October 2000 . cocaine and intravenous cocaine addicts (Williamson et al. 1997; Bartlett et al. 1997). For most cocaine addicts, symptoms abate significantly within the first day or two of detoxification, but there is also evidence of more persistent symptomatology, particularly paranoia (Manschreck et al. 1988). These psychotic symptoms are associated with increased craving and diminished likelihood of abstinence (Rosse et al. 1994; Williamson et al. 1997). Attempts to treat stimulant addicts with neuroleptic drugs for more extended periods of time generally have not been successful because of patients' extreme resistance to taking the medication (Gawin et al. 1989). For schizophrenia, psychosocial rehabilitative efforts that do not include adequate pharmacologic control of psychotic behavior are generally less effective than those that do (Hogarty et al. 1979). In the absence of an acceptable therapeutic agent, whether a similar situation occurs for stimulant addicts is unknown. 
Coordinated neurobiologic and genetic research has identified a pathophysiological aspect of schizophrenia that may also underlie psychotic symptoms in stimulant addicts. Schizophrenic patients have diminished inhibition of the P50 auditory evoked response to the second of two repeated stimuli (Adler et al. 1982; Boutros et al. 1991; Judd et al. 1992; Clementz et al. 1997). When two identical stimuli are presented $0.5 \mathrm{~s}$ apart, normal subjects have a significantly smaller P50 response to the second stimulus; whereas, schizophrenic subjects do not. This example of a sensory gating deficit is part of the neuronal pathophysiology that underlies the hypervigilance, poor sensory filtering, and decreased sustained attention that is characteristic of schizophrenia and other psychoses (Freedman et al. 1994). These elementary psychophysiological disturbances are also thought to underlie more complex symptoms, such as paranoid delusions and hallucinations (Venables 1964). An identical disturbance in the inhibition of the P50 auditory evoked response to repeated stimuli has been found in recently detoxified cocaine addicts by Fein and his group (Fein et al. 1996). The finding has also been replicated by Boutros, who demonstrated a significant correlation $(\mathrm{r}=0.852, p<$ .002) in cocaine addicts between the intensity of psychotic symptoms, as measured on the Wisconsin Psychosis Proneness Scale and loss of inhibition of the P50 response (Boutros et al. 1998). Boutros et al. also reported a significant correlation in cocaine addicts between loss of $\mathrm{P} 50$ inhibition and ratings of psychosis on the Cocaine Experience Questionnaire $(\mathrm{r}=0.760, p<.02)$. Thus, a similar pathophysiology may occur in stimulant abuse and schizophrenia.

However, this electrophysiological similarity may reflect different underlying neuronal mechanisms. For schizophrenia, the pathophysiological disturbance has been related to an abnormality in nicotinic acetylcholine-mediated neurotransmission. Pharmacologic experiments in animal models identified the cholinergic stimulation of hippocampal interneurons as a critical neuronal mechanism in the brain's ability to diminish its response to repeated stimuli. The receptor type mediating the response is the low affinity neuronal nicotinic receptor, for which the responsible gene is the $\alpha 7$ nicotinic receptor subunit gene (Luntz-Leybman et al. 1992). In schizophrenic patients, post-mortem studies show that the expression of this receptor is diminished in the hippocampus (Freedman et al. 1994). Genetic studies of the evoked potential abnormality showed that it seemed to be inherited in the families of schizophrenics as an autosomal dominant trait. Genetic linkage in a genome-wide scan showed significant linkage to a chromosome $15 q 14-15$ site, where the $\alpha 7$ nicotinic receptor subunit gene is also located (Freedman et al. 1997). Thus, independent genetic and neurobiological evidence indicates the failure of an $\alpha 7$ nicotinic receptor mechanism in schizophrenia. Treatment of patients or of nongating first-degree relatives with nicotine, either as nicotine-containing gum or by their own cigarette smoking, transiently normalizes their evoked potential inhibition (Adler et al. 1992,1993).

Although a nicotinic receptor abnormality is, thus, implicated as one pathophysiological aspect of schizophrenia, a noradrenergic mechanism can also cause loss of inhibition in the sensory gating paradigm. For example, decreased inhibition of the P50 response occurs in mania, with the decrease correlated with increased plasma levels of the noradrenergic metabolite 3-methoxy, 4-hydroxyphenylglycol (MHPG; Adler et al. 1990). When plasma MHPG levels return to normal during clinical treatment, the P50 inhibition also normalizes. Decreased inhibition also occurs in normal subjects after administration of the $\alpha-2$ adrenergic receptor antagonist yohimbine, which increases presynaptic release of norepinephrine (Adler et al. 1994). In schizophrenia, correlation of P50 inhibition with MHPG levels has also been found, but P50 inhibition remains abnormal, even when MHPG levels are within the normal range after neuroleptic treatment (Adler et al. 1990; Kang et al. 1997). Thus, schizophrenia itself probably involves a non-noradrenergic deficit; that is, the cholinergic deficit described above. McDougle et al.(1994) have demonstrated that noradrenergic dysregulation occurs in cocaine addicts and persists into the detoxification period. Yui et al. (1997) have related increased MHPG levels to psychotic symptoms. Recent genetic evidence associates cocaine-induced paranoia with an allelic variant of the dopamine $\beta$-hydroxylase gene, which lowers the level of the enzyme [REEFOL] (Cubells et al. 2000). Although dopaminergic dysregulation also occurs in cocaine addicts, abnormalities in the dopamine transporter are correlated with increased MHPG levels as well [REFO](Bowers et al. 1998). These findings suggest that noradrenergic dysregulation could be similarly responsible for diminished sensory inhibition in cocaine addicts.

Animal electrophysiological studies are consistent with these clinical observations. Increased noradrenergic neurotransmission induced pharmacologically by a variety of stimulant compounds causes loss of inhibition of auditory response to repeated stimuli (Adler et al. 1988; Stevens et al. 1991; Boutros et al. 1994). Norepinephrine interferes with the responses of inhibitory interneurons by a variety of mechanisms, including blockade of their synaptic activation (Doze et al. 1991). The noradrenergic effects of stimulant compounds can be blocked by noradrenergic receptor antagonists, but the effect is also reversed by nicotinic agonist administration (Stevens et al. 1991,1995). In particular, there is a loss of inhibition of the hippocampal auditory evoked response after chronic cocaine, which is then blocked by $\alpha 7$-nicotinic agonist administration (Stevens et al. 
1999). The presumed mechanism of action is a competition between nicotinic excitation of interneurons and noradrenergic inhibition of their response (Frazier et al. 1998). Although this interaction has been demonstrated in animals, it is not known if it is physiologically significant in human cocaine addicts.

The goal of the present study was to replicate Fein's and Boutros's findings that cocaine addicts have diminished auditory sensory inhibition as measured with the P50 response and to determine if the failure of inhibition is affected by nicotine administration.

\section{METHODS AND MATERIALS}

\section{Subjects}

The subjects were 11 cocaine addicts recruited from the Addiction Research and Treatment Service of the University of Colorado and the Drug Treatment Unit of the Denver Veterans Affairs Medical Center. The six males and five females ranged in age from 35 to 50 years old. Five were African Americans, two were Hispanic, and four were Caucasian. Six were divorced or separated, two were married, and three were single. Diagnoses were made by SCID IV-P interview. Eight fulfilled DSM-IV criteria for cocaine dependence, and three fulfilled criteria for cocaine abuse. All reported use of cocaine within 2 to 6 days of study. Three used intravenous cocaine, four smoked crack cocaine, two smoked free base, and two inhaled cocaine powder. Seven had positive urine drug screens for cocaine on the day of the study; four did not. All denied using cocaine on the day of study. Additional positive results of the urine drug screen included two positive for opiates and one positive for marijuana. There were multiple co-morbid diagnoses, including alcohol dependence or abuse, polydrug abuse, major depression, and post-traumatic stress disorder. Medications included selective serotonin reuptake inhibitors, but there were no tranquilizers or mood stabilizers, except for one patient taking valproic acid for post-traumatic stress disorder. None had personal or family histories of mania or schizophrenia. A summary of the DSM-IV diagnoses for each subject is given in Table 1; the only diagnosis all had in common was cocaine dependence or abuse. Seven were currently cigarette smokers, and four had never smoked. Fagerstrom scale scores for the smokers ranged from 3 to 12. Vital signs showed pulse and blood pressure within normal limits for all subjects. None of these parameters influenced baseline values or the effects of nicotine. All subjects gave informed consent and were paid compensation for participation in the study. The study was approved by the joint Institutional Review Board of the University of Colorado and the Denver VA Medical Center, in accordance with the Declaration of Helsinki.

\section{Experimental Procedures}

Subjects came to the laboratory at 9 AM; they had been instructed not to use cocaine from the time of enrollment in the study, which was 2 to 6 days before the study. They were not allowed to smoke within 2 hours of the initial recording. After a baseline P50 evoked potential recording, they received either placebo or nicotine-containing gum. The placebo used was a gum that had an herbal medicinal taste. Subjects were asked to close their eyes when given the gum, so that they did not see the color or labeling of the gum. None had regularly used nicotine gum before, so they could not differentiate active from placebo gum on the basis of taste.

One nonsmoker received $4 \mathrm{mg}$ of nicotine; all others received $6 \mathrm{mg}$. There were no adverse effects of the nicotine-containing gum reported or observed. Subjects were instructed to chew the gum until it was soft and then to hold it between the cheek and gum for $5 \mathrm{~min}$, expectorating any excess saliva. This strategy minimizes nausea from the nicotine entering the stomach and results in a rapid rise in nicotine level as it is absorbed from the buccal mucosa. Ten minutes after initiation of the nicotine or placebo treatment, the first posttreatment series of recordings were performed. Vital signs were also obtained. A second post-nicotine or placebo recording was performed $30 \mathrm{~min}$ after initiation of the nicotine or placebo treatment. Two hours later, the subjects received another baseline recording and then

Table 1. DSM IV Diagnoses of Subjects Determined by SCID IV-P Interview

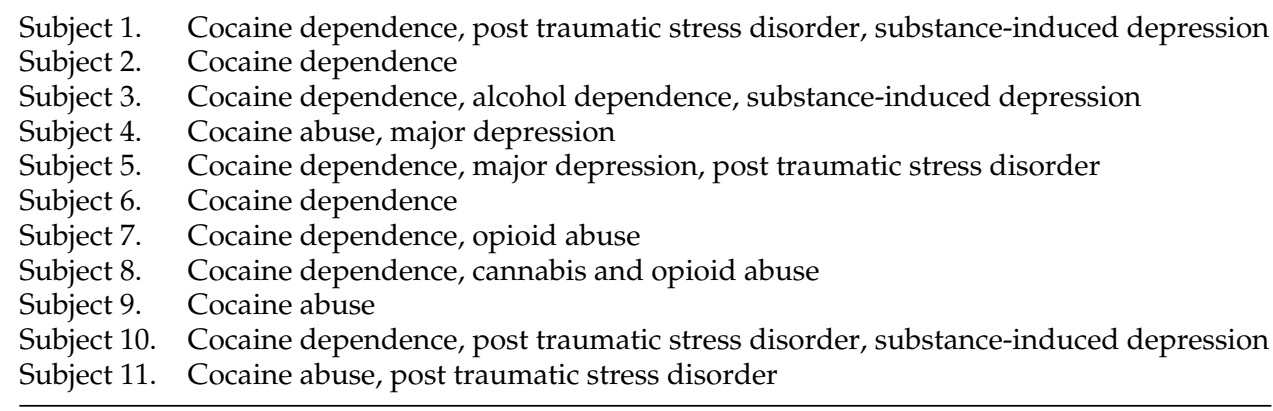


the other treatment. They received lunch between the two treatments. Five subjects received nicotine gum first; six received placebo first. Ten of the 11 subjects returned 10 days later for a repeat study. One subject refused to complete the placebo trial on the second day because of time constraints.

\section{Evoked Potential Recording}

Subjects lay supine on a hospital bed with their necks supported by pillows to minimize myogenic artifacts. They were instructed to remain awake, with their eyes open and fixed at a distant target. Electroencephalographic activity was monitored during the recording. If a subject showed prominent alpha activity, recording was halted and they were reminded to remain awake. If a subject entered sleep, the recording was halted for 2 min, and the previous trials were omitted from further analysis (Griffith et al. 1993). The auditory stimuli were rarefaction clicks, delivered $50 \mathrm{~dB}$ over the previously determined auditory threshold (Griffith et al. 1995). The stimuli were presented in trains of pairs, with an intrapair interval of $0.5 \mathrm{~s}$ and an interpair interval of $10 \mathrm{~s}$. Electroencephalographic activity was recorded from gold electrodes at $\mathrm{Cz}$ referenced to the ear. Additional electrodes recorded electro-oculographic activity from the right supraorbital ridge and lateral canthus.

Three sets of artifact-free responses to 16 paired stimuli were collected at each time point, so that a total of 48 trials were recorded at each of the three time points in the study. Trials that contained electroencephalographic or electro-oculographic activity greater than $30 \mu \mathrm{V}$ within $80 \mathrm{~ms}$ after the auditory stimulus were rejected at the time of recording. The averages were subsequently reviewed by an investigator blind to subject identity and treatment; averages that seemed to have eye movement or muscle artifacts were recomputed, with trials contributing to these artifacts rejected. Each set of accepted trials was averaged and filtered digitally with a $10-100 \mathrm{~Hz}$ bandpass. P50 waves were measured from the grand average of the three trials according to a previously described algorithm (Nagamoto et al. 1989). The conditioning P50 wave was identified as the most positive peak $40-80 \mathrm{~ms}$ after the conditioning stimulus, measured relative to the preceding negative trough. The test wave was identified as the most positive peak occurring after the test stimulus, within $\pm 10 \mathrm{~ms}$ of the latency of the conditioning response. The TC ratio was the ratio of the test to conditioning amplitudes. Other measurement strategies have been suggested, but the ratio measurement maximally differentiates schizophrenics from normals (Smith et al. 1994; Ward et al. 1996). The major alternative strategy suggested by Smith et al., consideration of test amplitude alone, showed effects of cocaine and nicotine that exactly paralleled those observed with TC ratio.

\section{Statistical Analysis}

Analyses of variance (ANOVAs) for effects of treatment (nicotine or placebo), day of treatment, order of treatment within the day, and time after administration of treatment were employed, using TC ratio, conditioning amplitude, and test amplitude as dependent variables. Tukey's HSD test with Kramer's modification was used for post-hoc comparison of values between nicotine and placebo trials at each time point. Student's $t$-tests were used to test the replication of previous findings of elevation of the ratio of the amplitudes of the test and conditioning P50 responses, as well as diminished amplitude of the initial P50 response, in the baseline recordings from detoxifying cocaine addicts (Fein et al. 1996; Boutros et al. 1993,1998). These tests were corrected for multiple testing by Bonferroni's method.

\section{RESULTS}

The Brief Psychiatric Rating Scale scores showed no significant difference between the two test days, for either the total score (day 1, $35.0 \pm 13.4$; day 2, $29.7 \pm 12.6$ ) or the psychosis subscore (day 1, $9.6 \pm 4.6$; day 2, $6.6 \pm$ 3.3). These scores are consistent with psychological distress, including mild to moderate psychotic symptoms, in those patients who were selected only for their ability to remain in the detoxification programs.

The ratio of the test to conditioning P50 response (TC ratio) was also elevated both days over values previously found in normal subjects (Figure 1). Examination of the amplitudes of the responses to the conditioning and test stimuli showed that the amplitude of the conditioning response was decreased from normal values and that the test amplitude was not significantly different. These findings replicate those previously observed by Fein et al. (1996) and Boutros et al. (1993;1998).

On both days, the administration of nicotine decreased the TC ratio to normal levels (Figures 2,3). The effect was brief, with recovery toward baseline abnormal levels $20 \mathrm{~min}$ after nicotine administration. The effect was not observed with placebo administration. ANOVA showed a significant effect of treatment $(\mathrm{F}=$ 7.783, df $1,98, p=.006$ ) and a significant treatment by time interaction ( $\mathrm{F}=3.60$, df 2,48, $p=.031$ ). Significant differences between placebo and nicotine treatment were observed only at the 10-min time point after nicotine administration (Figure 4). There was no effect of the patient's having a positive or negative urine test for cocaine and its metabolites on the day of the recording $(\mathrm{F}=0.24$, df 1,112, $p=.24)$. Similar ANOVAs were performed for the amplitudes of the conditioning and test responses separately. There was a significant interaction between treatment and time before or after treatment only for the test amplitude ( $\mathrm{F}=4.31$, df 2,98, $p=$ 


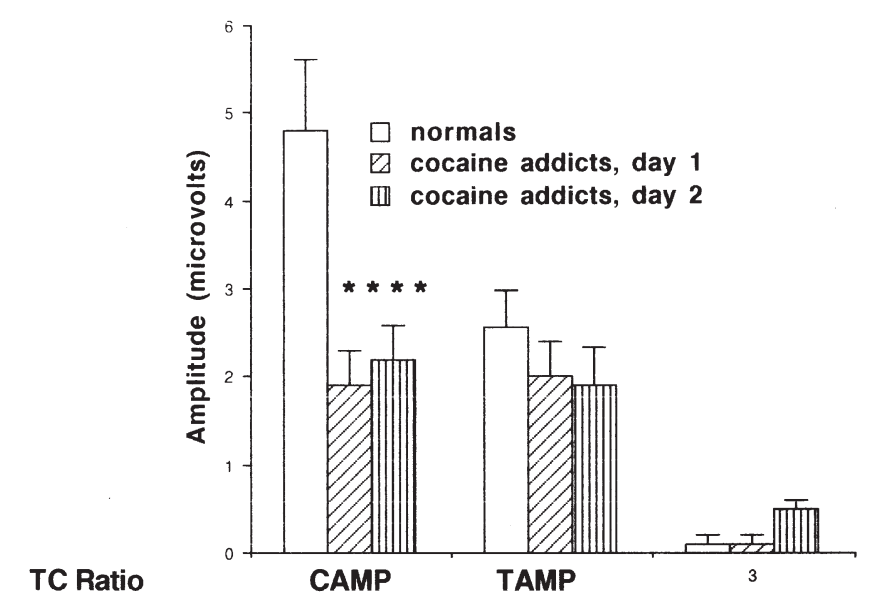

Figure 1. Comparison of the ratio of test to conditioning amplitudes (TC ratio), conditioning P50 amplitude (CAMP), and test P50 amplitude (TAMP) for normals ( $n=10$, from Griffith et al. 1995) and the cocaine addicts $(n=11$ day $1, n=$ 10 day 2 ). ${ }^{*} p<.05,{ }^{* *} p<.01$ by Student's $t$ test. For TC ratio, day $1, t=3.82$, df 19, $p<.001$ (Bonferroni corrected $p<$ .001 ); day $2, t=2.44$, df 18, $p<.05$ (Bonferroni corrected $p=$ .150 , not significant). For CAMP, day $1, t=3.26$, df $19, p<$ .001 (Bonferroni corrected $p=.008$ ); day $2, t=2.85, \mathrm{df} 18, p<$ .01 (Bonferroni corrected $p=0.06$, not significant).

.016). As observed for TC ratio, significant effects of nicotine on test amplitude, compared to placebo, occurred at the 10-min time point following nicotine administration (Table 2). Thus, the effects of nicotine on the TC ratio primarily represent a significant decrease in the P50 amplitude in the test response.

The latencies of the conditioning and test responses were not significantly affected by the treatment conditions. Blood pressure and pulse were also monitored to determine if they were affected by the treatment, but no significant changes were observed.

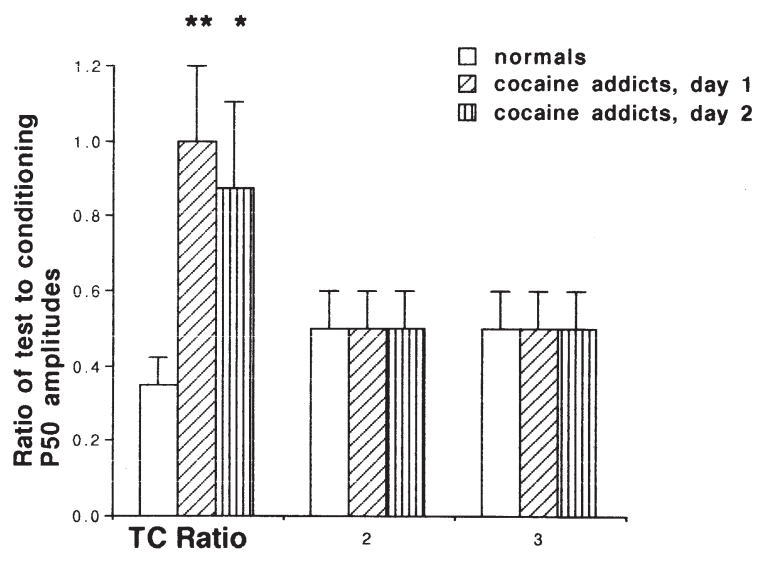

Figure 2. Comparison of effects of nicotine and placebo on the on the ratio of test to conditioning P50 amplitude on day 1 (upper graph) and day 2 (lower graph). ${ }^{*} p<.01$ by Tukey's HSD for the difference between nicotine and placebo treatment at this time point on both days.

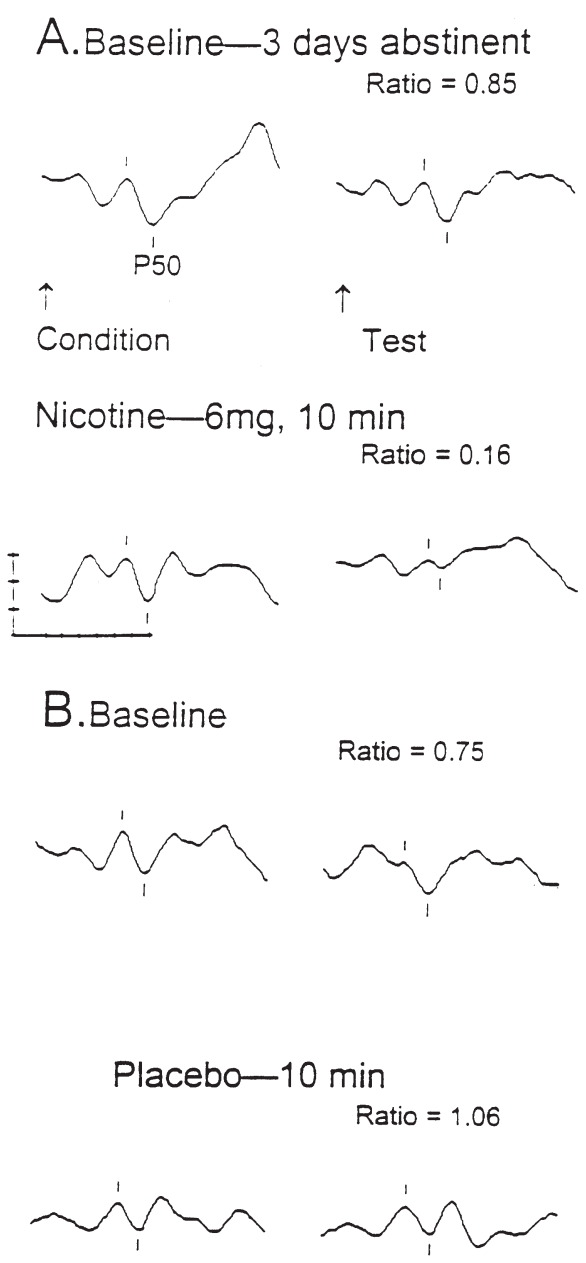

Figure 3. Auditory evoked potentials recorded from a detoxifying cocaine addict, comparing the effects of nicotine (A) and placebo (B). The conditioning and stimuli (arrows) were delivered $0.5 \mathrm{~s}$ apart. The P50 was identified (tic below waveform) and measured relative to the preceding negative trough (tic above waveform) by a computer algorithm described in the text. Vertical calibration units are $-2 \mu \mathrm{V}$; horizontal units are $10 \mathrm{msec}$.

\section{DISCUSSION}

This study has replicated the finding that cocaine addicts have diminished inhibitory sensory gating, as measured using the P50 auditory response. In schizophrenia, this abnormality is correlated with decreased vigilance and is thought to be a possible elementary substrate of more complex abnormalities, including hallucinations and delusions (Cullum et al. 1993). Fein et al. (1996) also found that the abnormality persists during the first 2 weeks of cocaine abstinence, which suggests that any mental dysfunction related to the abnormality would be similarly long lasting and might adversely affect psychosocial treatment. A similar loss of inhibition of sensory response has been observed in 
Table 2. Effects of Nicotine or Placebo on P50 Responses to the Conditioning and Test Stimuli in Detoxifying Cocaine Addicts

\begin{tabular}{lccc}
\hline & Baseline & 10 Min & 30 Min \\
\hline $\begin{array}{l}\text { Day 1: } \\
\quad \text { Conditioning amplitude }\end{array}$ & & & \\
$\quad$ Nicotine & $3.7 \pm 2.0$ & $4.2 \pm 2.2$ & $3.2 \pm 2.0$ \\
$\quad$ Placebo & $1.9 \pm 1.3$ & $2.9 \pm 1.7$ & $2.9 \pm 1.9$ \\
$\quad$ Test amplitude & & & \\
$\quad$ Nicotine & $2.7 \pm 2.1$ & $1.7 \pm 1.9^{a}$ & $1.9 \pm 1.4$ \\
$\quad$ Placebo & $2.0 \pm 1.3$ & $3.1 \pm 1.3$ & $1.5 \pm 1.3$ \\
Day 2: & & & \\
$\quad$ Conditioning amplitude & & & \\
$\quad$ Nicotine & $3.0 \pm 1.5$ & $4.4 \pm 1.3$ & $2.3 \pm 1.0$ \\
$\quad$ Placebo & $2.2 \pm 1.2$ & $3.7 \pm 1.4$ & $2.4 \pm 1.7$ \\
$\quad$ Test amplitude & & & \\
$\quad$ Nicotine & $2.2 \pm 1.0$ & $1.9 \pm 1.6^{b}$ & $1.7 \pm 2.2$ \\
$\quad$ Placebo & $1.9 \pm 1.4$ & $3.6 \pm 1.7$ & $2.1 \pm 1.3$ \\
\hline
\end{tabular}

All amplitudes are in microvolts, mean \pm SD.

${ }^{a, b}$ Difference between nicotine and placebo treatment at this time point significant by Tukey's HSD $(p<.01)$.

animals after several weeks of cocaine treatment (Boutros et al. 1994; Stevens et al. 1999), so that the abnormality is likely to be a consequence of cocaine selfadministration. The deficit seems to be a persistent consequence of cocaine administration, because its presence does not depend upon the patients' having cocaine or its metabolites in the urine. Other neurophysiological abnormalities related to increased noradrenergic neurotransmission have also been observed to persist for several weeks after relatively brief periods of stimulant administration (Sorensen et al. 1982). It is notable that this abnormality occurred in patients who were not preselected to have psychiatric comorbidity. The only selection criterion was that they remain in the treatment setting for at least 2 days. Furthermore, only one of the 11 patients did not remain in treatment for the next 10 days. Despite this relatively good response to treatment, these patients showed mild to moderate psychotic symptoms on the Brief Psychiatric Rating Scale and abnormal electrophysiological responses in the P50 conditioning-testing paradigm. Fein et al. (1996) observed a similar incidence of abnormal P50 inhibition in an unselected group of detoxifying cocaine addicts.

The cocaine addicts in this study included some with various co-morbid conditions, including such other psychiatric disorders as depression and PTSD and abuse of other substances. Such co-morbid conditions are typical of cocaine addicts (Brown et al. 1998). Heavy cigarette smoking is also typical of cocaine addicts (Wiseman and McMillan 1998a). The addicts also differed in their preferred routine of cocaine administration. None of these conditions seemed to affect the abnormality in P50 inhibition or its response to nicotine administration. Psychotropic medication use in general has not been associated with abnormalities in P50 gating (Baker et al. 1987).

The effects of nicotine on the auditory evoked potential were similar to those observed in schizophrenics and their relatives (Adler et al. 1992;1993). The dose re-
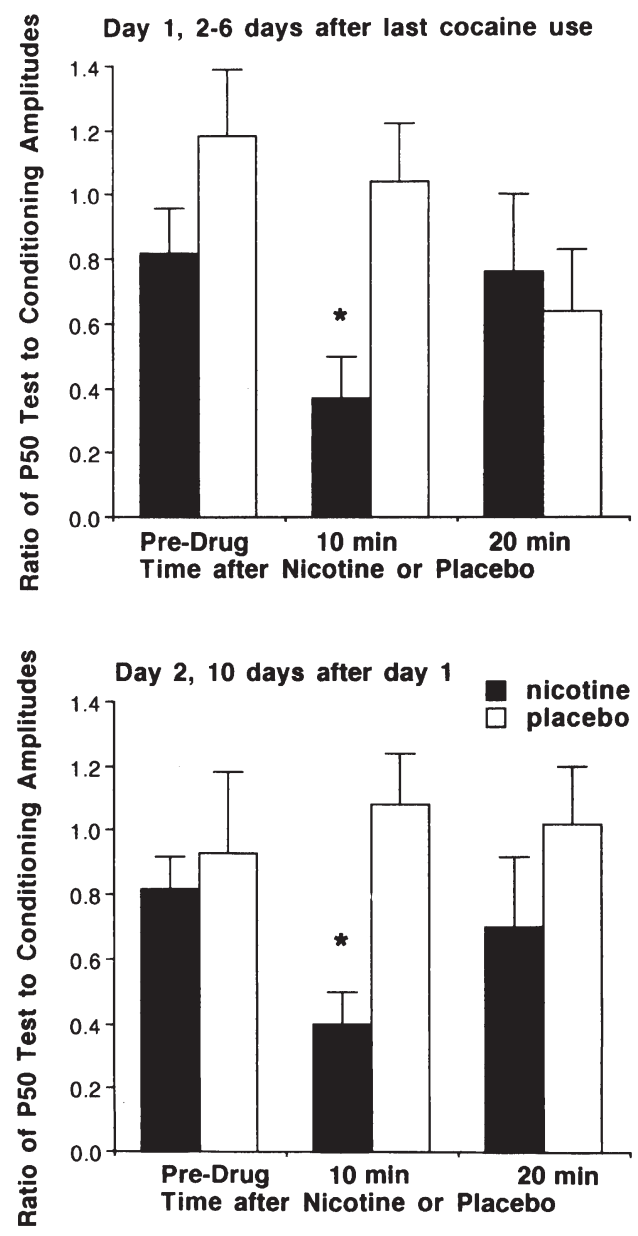

Figure 4. P50 Ratios (Test/Conditioning) as a function of treatment and time. The top graph is for Day 1 (2-8 days after last cocaine use). The bottom graph is 10 days later for each subject. The vertical axis shows the P50 ratio. The horizontal axis is time: pretreatment (baseline), 10 minutes after treatment, and 20 minutes after treatment. Results for nicotine are graphed in black. Results for placebo are colorless. All values are mean \pm s.d. Only the values at 10 minutes were statistically significant $(*)$, which is consistent with our previous studies of nicotine effects in schizophrenic patients and their relatives. For Day 1 (10 min, 11 subjects): Mean P50 ratio: nicotine $-0.38 \pm 0.37$ s.d.; placebo: $1.05 \pm 0.55$ s.d., separate variance $\mathrm{t}$ test $=-3.36, \mathrm{df}=17.5, p=.004$ uncorrected, $p=.01$ Bonferroni adjusted. For Day 2 (10 minutes: 10 subjects completed placebo day, 9 of the 10 had usable data for the nicotine day at the 10 minute period): Mean P50 ratio: nicotine $-0.40 \pm 0.29$ s.d., placebo: $1.07 \pm 0.54$ s.d., separate variance $\mathrm{t}$ test: $\mathrm{t}=-3.31$, d.f. $=11.9, p=.006$ uncorrected, $p=.01$ Bonferroni adjusted. 
quirement was similarly high; $6 \mathrm{mg}$ is the equivalent of about three cigarettes (Benowitz et al. 1988). A similar time course of effect and a similar effect size were observed in schizophrenic patients, regardless of whether they received gum or self-administered nicotine in the form of cigarettes (Adler et al. 1992,1993). Both the P50 auditory evoked potential and a smooth pursuit eye movement abnormality are normalized in schizophrenics with a similar time course and dose requirement (Olincy et al. 1998), suggesting that these parameters of response are not unique to the administration route or to the physiological abnormality under study.

The $\alpha 7$ nicotinic receptor is a ligand-gated ion channel (Lindstrom 1996). Nicotine or acetylcholine bind to the receptor, which then opens a channel that admits cations into the cell. Nicotine remains bound to the channel as it closes, resulting in an inactivated or desensitized state of the receptor. The $\alpha 7$ receptor, as studied in oocytes, is also more insensitive to nicotine than most other neuronal nicotinic receptors. Thus, the rapid time course of activation and deactivation and the high dose requirement are intrinsic to the $\alpha 7$ receptor mechanism (Lindstrom 1996). The bolus of nicotine from a cigarette or from rapid gum chewing is an ideal way to activate the receptor maximally. Studies in brain slices in vitro suggest that effects on the $\alpha 7$ receptor occur at doses consistent with nicotine levels achieved by smokers (McGehee et al. 1995; Gray et al. 1996). Attempts to activate the receptor with longer-lasting, lower doses would be expected to increase the effects of desensitization. The phenomenon of desensitization may help to explain why nicotine is not immediately ameliorative of schizophrenic symptoms and why nicotine withdrawal does not seem to result in a significant increase in psychotic symptoms of schizophrenic patients (Dalack et al. 1999). We have shown that treatment of schizophrenic patients with nicotine-containing transdermal patches, indeed, does not result in prolonged normalization of response, but rather, increased receptor desensitization (Griffith et al. 1998). Consideration of the time course of desensitization of the $\alpha 7$-nicotinic receptor is important for understanding the mechanism of other observations of the interaction between cocaine and nicotine. A recent study using transdermal nicotine patches showed that, after 3 hours, the patch increases cocaine craving (Reid et al. 1998). The Griffith et al. study (1998) demonstrates that effects after 3 hours are more likely to be caused by receptor desensitization than by receptor activation. Thus, receptor desensitization may not only abbreviate the duration of nicotine's effect on sensory gating, but it may also cause an undesirable increase in craving.

These properties make nicotine an undesirable therapeutic agent for psychotic symptoms in cocaine abuse. If the $\alpha 7$ nicotinic receptor is to be considered as therapeutic target for drug development, it would be desir- able to develop more specific agonists that might also have less desensitization. Desensitization involves an allosteric change in the nicotinic receptor, which might be differentially activated by alternative agonists. There are currently no other nicotinic agonists available for human use. 3-(2,4)-dimethoxybenzylidine anabaseine (DMXBA) has positive effects on a similar loss of sensory inhibition produced by chronic cocaine administration in animals (Stevens et al. 1999). DMXBA is a mixed agonist-antagonist at the $\alpha 7$ receptor of both humans and rodents, with blocking activity at $\alpha 4$ receptors, the principal higher affinity receptor (DeFiebre et al. 1995; Briggs et al. 1997). Although DMXBA did not show long-lasting effects, it also did not show any loss of effect when the same dose was repeated 40 minutes later. In contrast, nicotine had no effect when it was administered 40 minutes after an initial dose. The similar effects of nicotine in both the animal and human studies suggest that the animal studies might be predictive of other nicotinic agonist effects in humans. DMXBA, thus, may be a prototypic molecule for a drug that might produce antipsychotic effects in cocaine addicts by a novel therapeutic mechanism. It is noteworthy that mecamylamine, a channel blocker that antagonizes all of the nicotinic receptors except the $\alpha 7$ receptor, has been reported to decrease cocaine craving (Reid et al. 1999). By leaving only the $\alpha 7$ component of nicotinic cholinergic neurotransmission active, mecamylamine might have similar effects to an $\alpha 7$ agonist. Mecamylamine failed to block effects of nicotine agonists on P50 gating in cocaine-treated animals (Stevens et al. 1999).

Effects of nicotine on psychotic symptoms were not formally measured in this study, because the extremely short time course of nicotine's effects was not felt to be sufficient for reliable clinical observation. Nevertheless, patients uniformly reported a transient qualitative decrease in anxiety and paranoia, consistent with the physiological changes observed. Similar reports of beneficial effects of cigarette smoking on paranoia and anxiety in cocaine addicts have been obtained by other investigators, who have also reported that addicts who remain abstinent from cocaine have significantly greater rates of heavy smoking than nonabstinent addicts (Wiseman and McMillian 1998a, 1998b). Thus, nicotine use may ultimately influence drug-seeking behavior. Although a relationship between increased drug-seeking behavior and psychotic symptoms has been observed clinically (Rosse et al. 1994), the mechanism of this relationship is unknown. It has been observed, however, than sensitization to stimulants is common in both chronic stimulant abuse and in endogenous psychoses (Yui et al. 1999). Thus, the similar effect of nicotine on an electrophysiological abnormality common to both cocaine abuse and schizophrenia, as observed in the present study, one of several examples of convergent pathophysiological mechanisms. 


\section{ACKNOWLEDGMENTS}

The authors acknowledge the role of Eliza Porter, R.N., in the clinical care of VA subjects. This research was supported by the VA Medical Research Service and UPSHS Grants MH10466, MH00728, MH44212, MH3831, and NARSAD.

\section{REFERENCES}

Adler LE, Gerhardt GA, Franks R, Baker N, Nagamoto H, Drebing C, Freedman R (1990): Sensory physiology and catecholamines in schizophrenia and mania. Psychiat Res 31:297-309

Adler LE, Hoffer LJ, Griffith J, Waldo M, Freedman R (1992): Normalization by nicotine of deficient auditory sensory gating in the relatives of schizophrenics. Biol Psychiat 32:607-616

Adler LE, Hoffer L, Nagamoto HT, Waldo MC, Kisley MA, Griffith JM (1994): Yohimbine impairs P50 auditory sensory gating in normal subjects. Neuropsycholpharmacology 10:249-257

Adler LE, Hoffer LD, Wiser A, Freedman R (1993): Normalization of auditory physiology by cigarette smoking in schizophrenic patients. Am J Psychiat 150:1856-1861

Adler LE, Pachtman E, Franks RD, Pecevich M, Waldo MC, Freedman R (1982): Neurophysiological evidence for a defect in neuronal mechanisms involved in sensory gating in schizophrenia. Biol Psychiat 17:639-654

Adler LE, Pang K, Gerhardt G, Rose GM (1988): Modulation of the gating of auditory evoked potentials by norepinephrine: Pharmacological evidence obtained using a selective neuro-toxin. Biol Psychiat 24:179-190

Angrist G, Sathanthan G, Wilk S, Gerson S (1974): Amphetamine psychosis: Behavioral and biochemical aspects. J Psychiat Res 11:13-23

Baker N, Alder LE, Franks RD, Waldo M, Berry S, Nagamoto H, Muckle A, Freedman R (1987): Neurophysiological assessment of sensory gating in psychiatric inpatients: Comparison between schizophrenia and other diagnoses. Biol Psychiat 22:603-617

Bartlett E, Hallin A, Chapman B, Angrist B (1997): Selective sensitization to the psychosis-inducing effects of cocaine: A possible marker for addiction relapse vulnerability? Neuropsychopharmacology 16:77-82

Benowitz NL, Porchet H, Sheiner L, Jacob P 3d (1988): Nicotine absorption and cardiovascular effects with smokeless tobacco use: Comparison with cigarettes and nicotine gum. Clin Pharmacol Ther 44:23-28

Boutros N, Krystal J, Gerlenter J (1998): Sensory gating and cocaine-induced paranoia. Biol Psychiat 43:89S

Boutros N, Uretsky N, Berntson G, Bornstein R (1994): Effects of cocaine on sensory inhibition in rats: Preliminary data. Biol Psychiat 36:242-248

Boutros N, Zouridakis G, Overall J (1991): Replication and extension of P50 findings in schizophrenia. Clin Electroencephalograp 22:40-45

Boutros N, Zouridakis G, Rustin T, Peabody C, Warner, D (1993): The P50 component of the auditory evoked potential and subtypes of schizophrenia. Psychiat Res 47:243-254

Bowers MB, Malison RT, Seibyl JP, Kosten TR (1998): Plasma homovanillic acid and the dopamine transporter during cocaine withdrawal. Biol Psychiat 43:278-281

Brady KT, Lydiard RB, Malcolm R, Ballenger JC (1991): Cocaine-induced psychosis. J Clin Psychiat 52:509-512

Briggs CA, Anderson DJ, Brioni, JD, Buccafusco, JJ, Buckley MJ, Campbell, JE, Decker MW, Donnelly-Roberts D, Elliott RI, Gopalakrishnan M, Holladay MW, Hui YH, Jackson WJ, Kim DJ, Marsh KC, O'Neill A, Prendergast MA, Ryther KB, Sullivan JP, Arneric SP (1997): Functional characterization of the novel neuronal nicotinic acetylcholine receptor ligand GTS-21 in vitro and in vivo. Pharmacol Biochem Behav 57:231-241

Brown RA, Monti PM, Myers MG Rivinius T, Dubreuil ME, Rosenhow DJ (1998): Depression among cocaine abusers in treatment: Relation to cocaine abuse and alcohol use and treatment outcome. Am J Psychiat 155:220-225

Clementz BA, Geyer MA, Braff DL (1997): P50 suppression among schizophrenic and normal comparison subjects: A methodological analysis. Biol Psychiat 41:1035-1044

Cubells JF, Kranzler HR, McCance-Katz E, Anderson GM, Malison RT, Price LH, Gelernter J (2000): A haplotype at the DBH locus, associated with low plasma dopamine beta-hydroxylase activity, also associates with cocaineinduced paranoia. Mol Psychiat 5:56-63

Cullum CM, Harris JG, Waldo MC, Smernoff E, Madson A, Nagamoto HT, Griffith J, Adler LE, Freedman R (1993): Neurophysiological and neuropsychological evidence of attentional dysfunction in schizophrenia. Schiz Res 10:131-141

Dalack GW, Becks L, Hill E, Pomerleau OF, Meador-Woodruff JH(1999): Nicotine withdrawal and psychiatric symptoms in cigarette smokers with schizophrenia. Neuropsychopharmacology 21:195-202

DeFiebre CM, Meyer EM, Henry JC, Muraskin SI, Kem W, Papke RL (1995): Characterization of a series of anabaseine-derived compounds reveals that the 3-(4)-dimethylaminocinamylidine derivative is a selective agonist at neuronal nicotinic alpha7 $/{ }^{125} \mathrm{I}-\alpha$-bungarotoxin receptor subtypes. Mol Pharmacol 47:164-171

Doze VA, Cohen GA, Madison DV (1991): Synaptic localization of adrenergic disinhibition in the rat hippocampus. Neuron 6:889-900

Fein G, Biggins C, MacKay S (1996): Cocaine abusers have reduced auditory $\mathrm{P} 50$ amplitude and suppression compared to both normal controls and alcoholics. Biol Psychiat 39:955-965

Frazier CJ, Buhler AV, Weiner JL, Dunwiddie TV (1998): Synaptic potentials mediated via alpha-bungarotoxinsensitive nicotinic acetylcholine receptors in rat hippocampal interneurons. J Neurosci 18:8228-8235

Freedman R, Adler LE, Bickford P, Byerley W, Coon H, Cullum MC, Griffith JM, Harris JG, Leonard S, Miller C, Myles-Worsley M, Nagamoto HT, Rose GM, Waldo M (1994): Schizophrenia and nicotinic receptors. Harv Rev Psychiat 2:179-192

Freedman R, Myles-Worsley M, Orr-Urtreger A, Olincy A, Davis A, Polymeropoulos M, Holik J, Hoff M, Rosenthal J, Waldo MC, Reimherr F, Wender P, Yaw J, Young DA, 
Breese CR, Adams C, Patterson D, Adler LE, Kruglyak L, Leonards S, Byerley W (1997): Linkage of a neurophysiological deficit in schizophrenia to a chromosome 15 locus. Proc Natl Acad Sci USA 94:587-593

Gawin, FH, Kleber, HD, Byck R, Rounsaville B, Kosten TR, Jatlow P, Morgan C (1989): Desipramine facilitation of initial cocaine abstinence. Arch Gen Psychiat 46:117-121

Gray R, Rajan AS, Radcliffe KA, Yakehiro M, Dani JA (1996): Hippocampal synaptic transmission enhanced by low concentrations of nicotine. Nature 383:670-671

Griffith J, Waldo M, Adler LE, Freedman R (1993): Normalization of auditory sensory gating in schizophrenic patients after a brief period for sleep. Psychiat Res 49:29-39

Griffith J, Hoffer LD, Adler LE, Zerbe GO, Freedman R (1995): Effects of sound intensity on a midlatency evoked response to repeated auditory stimuli in schizophrenic and normal subjects. Psychophysiol 32:460-466

Griffith J, O'Neill JE, Petty F, Garver D, Young D, Freedman, $R$ (1998): Nicotine receptor desensitization and sensory gating deficits in schizophrenia. Biol Psychiat 44:98-106

Hogarty GE, Schooler NR, Ulrich R, Mussare F, Ferro P, Herron E (1979): Fluphenazine and social therapy in the aftercare of schizophrenic patients. Arch Gen Psychiat 36:1283-1294

Judd LJ, McAdams L, Budnick B, Braff, DL (1992): Sensory gating deficits in schizophrenia: New results. Am J Psychiat 149:488-493

Kang DY, Poole J, McCallin K, Fein G, Vinogradov S (1997): Sensory gating deficit in schizophrenia: Relation to catecholamine metabolites. Schizo Res 24:234

Lindstrom J (1996): Neuronal nicotinic acetylcholine receptors. In Narahaski T (ed), Ion Channels. New York, Plenum Press, pp 377-450

Luntz-Leybman V, Bickford PC, Freedman R (1992): Cholinergic gating of response to auditory stimuli in rat hippocampus. Brain Res 587:130-136

Manschreck TC, Laughery JA, Weisstein CC, Allen D, Humbleston B, Neville M, Podlewski H, Mitra N (1988): Characteristics of free base cocaine psychosis. Yale J Biol Med 61:115-122

McDougle CJ, Black JE, Malison RT, Zimmerman RC, Kosten TR, Heninger GR, Price LH (1994): Noradrenergic dysregulation during discontinuation of cocaine use in addicts. Arch Gen Psychiat 51:713-719

McGehee DS, Heath MJ, Gelber S, Devay P, Role LW (1995): Nicotine enhancement of fast excitatory transmission in CNS by presynaptic receptors. Science 269:1681-1682

Nagamoto HT, Adler LE, Waldo MC, Freedman R (1989): Sensory gating in schizophrenics and normal controls: Effects of changing stimulation interval. Biol Psychiat 25:549-561

Olincy A, Ross RG, Young DA, Roath M, Freedman, R (1998): Improvement in smooth pursuit eye movements after cigarette smoking in schizophrenic patients. Neuropsychopharmacology 18:175-185
Reid MS, Mickalian JD, Deluuchi KL, Hall MS, Berger SP (1998): An acute dose of nicotine enhances cue-induced cocaine craving. Drug Alc Depend 49:95-104

Reid MS, Mickalian JD, Delucchi KL, Berger SP (1999): A nicotine antagonist, mecamylamine, reduces cue-induced cocaine craving in cocaine-dependent subjects. Neuropsychopharmacology 20:297-307

Rosse RB, Alim TN, Vocci FJ Jr, Hess AL, Johri SK, Deutsch SI (1994): Greater increases in cocaine cue-induced craving and pupillary size in cocaine addicts endorsing cocaine-induced paranoia. Biol Psychiat 35:693

Smith DA, Boutros NN, Schwarzkopf SB (1994): Reliability of P50 auditory event-related potential indices of sensory gating. Psychophysiology 31:495-502

Sorensen S, Johnson S, Freedman R (1982): Persistent effects of amphetamine on cerebellar purkinje neurons following chronic administration. Brain Res 247:365-371

Stevens KE, Fuller LL, Rose GM (1991): Dopaminergic and noradrenergic modulation of amphetamine-induced changes in auditory gating. Brain Res 555:91-98

Stevens KE, Kem WR, Freedman R (1999): Selective $\alpha 7$ nicotinic receptor stimulation normalizes cocaine-induced loss of hippocampal sensory inhibition in $\mathrm{C} 3 \mathrm{H}$ mice. Biological Psychiat 46:1443-1450

Stevens KE, Meltzer J, Rose GM (1995): Nicotinic cholinergic normalization of amphetamine-induced loss of auditory gating in freely-moving rats. Psychopharmacology 119:163-170

Venables P (1964): Input dysfunction in schizophrenia. Prog Exp Pers Res 1:1-47

Ward PB, Hoffer LD, Liebert BJ, Catts SV, O'Donnell M, Alder LE (1996): Replication of a P50 auditory gating deficit in Australian schizophrenic patients. Pyschiat Res 64:121-135

Williamson S, Gossop M, Powis B, Griffiths P, Fountain J, Strang J (1997): Adverse effects of stimulant drugs in a community sample of drug users. Drug Alc Depend 44:87-94

Wiseman EJ, McMillan DE (1998a): Rationale for cigarette smoking and for mentholation preference in cocaineand nicotine-dependent outpatients. Comprehen Psychiat 39:358-363

Wiseman EJ, McMillan DE (1998b): Relationship of cessation of cocaine use to cigarette smoking in cocaine-dependent outpatients. Am J Drug Alc Abuse 24:617-625

Yui K, Goto K, Ikemoto S, Ishiguro T (1997): Monoamine neurotransmitter metabolites and spontaneous recurrence of methamphetamine psychosis. Brain Res Bull $43: 25-33$

Yui K, Goto K, Ikemoto S, Ishiguro T, Angrist B, Duncan GE, Sheitman BB, Lieberman JA, Bracha SH, Ali SF (1999): Neurobiological basis of relapse prediction in stimulant-induced psychosis and schizophrenia: The role of sensitization. Molec Psychiat 4:512-523 